\title{
Repair of Protease-damaged Elastin in Neonatal Rat Aortic Smooth Muscle Cell Cultures
}

\author{
Phillip J. Stone, Shirley M. Morris, Bernice M. Martin, Mary P. McMahon, Barbara Faris, and Carl Franzblau
}

Department of Biochemistry, Boston University School of Medicine, Boston, Massachusetts 02118

\begin{abstract}
The objective of this study was to investigate the elastin repair process in the rat aortic smooth muscle cell culture after proteolytic injury. Although little studied in vivo, elastin repair is thought to occur through a sequential process involving enzymatic removal (debridement) of damaged fibers followed by synthesis of tropoelastin, its subsequent processing, and eventual incorporation into new insoluble elastin. A second repair mechanism of proteolytically damaged elastin in a culture system is reported here. Repair in this system relates directly to restoration of resistance to elastin solubilization by hot alkali. As expected, severe injuries were observed with porcine pancreatic elastase (PPE). Using PPE, only 6\% of the elastin, relative to control, was resistant to hot alkali immediately after elastase treatment. 4 wk later, resistance to hot alkali had increased dramatically to a mean of $90 \%$. Repair took longer after injury with $75 \mu \mathrm{g}$ of PPE as compared with $50 \mu \mathrm{g}$ of PPE. The limited elastic fiber proteolysis induced by either human neutrophil elastase or porcine trypsin was repaired in culture within 2 wk. Elastin that had been radiolabeled with $\left[{ }^{3} \mathbf{H}\right] l y s i n e$ 4-5 wk before injury was converted from a hot $\mathrm{NaOH}$-susceptible to a $\mathrm{NaOH}$-resistant elastin fraction during recovery from PPE injury. At the same time, the frayed elastic fibers that were seen with the electron microscope immediately after PPE treatment were replaced by continuous bands of elastin that resembled those in control cultures. Restoration of $\mathrm{NaOH}$ resistance did not require a net increase in total cell layer elastin, suggesting that relatively little new tropoelastin incorporation into the cell layer was required for this type of repair. These results suggested a salvage repair mechanism for proteolytically damaged elastin.
\end{abstract}

\section{Introduction}

Elastin is a cross-linked protein biopolymer with rubber-like tensile properties that make it highly suited for its role in the lung, major arteries, and other organs (1). The proteolytic degradation of elastin has been the subject of intensive investigation for many years. Much of the interest stems from the possi-

Portions of this work were presented at the Federation of American Societies for Experimental Biology Meeting, Washington, DC, 29 March, 1987.

Address reprint requests to Dr. Phillip J. Stone, Department of Biochemistry, Boston University School of Medicine, Boston University Medical Center, 80 East Concord Street, Boston, MA 02118.

Received for publication 10 November 1987 and in revised form 4 April 1988.

J. Clin. Invest.

(C) The American Society for Clinical Investigation, Inc

$0021-9738 / 88 / 11 / 1644 / 11 \$ 2.00$

Volume 82, November 1988, 1644-1654 ble involvement of such elastolysis in the pathology of human diseases, including emphysema and atherosclerosis (2). Relatively little work has been directed to processes involving the repair of this elastin. Mature elastin is insoluble and is often defined operationally as that protein which remains after treatment of a tissue homogenate with $0.1 \mathrm{~N} \mathrm{NaOH}$ for $45 \mathrm{~min}$ at $98^{\circ} \mathrm{C}(3)$. It contains interchain cross-links, including desmosine (DES) ${ }^{1}$ and isodesmosine (IDES), that are responsible for this insolubility.

Recent reports suggest that elastin peptides, which can arise during proteolysis, initiate signal transduction by interacting with cell recognition sites. For example, human leukocytes respond in vitro to elastin peptides by chemotaxis $(4,5)$. Mononuclear cells, fibroblasts, and smooth muscle cells exhibit a rapid increase in cytosolic concentrations of calcium ions $(6,7)$. We have previously used neonatal rat aortic smooth muscle cell cultures as model systems to study elastic fiber injury by proteases $(8,9)$. Morphologically the cell layers in the culture resemble the aorta, with elastin accounting for as much as $50 \%$ of the total protein. Unlike elastin of control cultures, the elastin of protease-treated cultures is partially solubilized by incubation in hot alkali $(8,9)$. In this report, we studied the fate of protease-damaged elastin. Our data show that this elastin is converted to the hot alkali-resistant form. A hitherto undescribed salvage process may be responsible for this repair.

\section{Methods}

Protease treatment of smooth muscle cell cultures. Neonatal rat smooth muscle cells were isolated from the aortae of 1-3-d-old Sprague-Dawley rats and cultured in DME containing $3.7 \mathrm{~g} /$ liter sodium bicarbonate, $100 \mathrm{U} / \mathrm{ml}$ penicillin and $100 \mu \mathrm{g} / \mathrm{ml}$ streptomycin, $10 \%$ fetal bovine serum, and $20 \mu \mathrm{g} / \mathrm{ml}$ sodium ascorbate as described previously (9). Each experiment was carried out on the same cohort of cells after trypsinization and reseeding into $25-\mathrm{cm}^{2}$ flasks for first passage. All experiments contained control and enzyme-treated cultures. In some experiments, cells were pulsed with $\mathrm{L}\left[4,5-{ }^{3} \mathrm{H}\right]$ lysine- $\mathrm{HCl}$ for $24 \mathrm{~h}$ within the first 2 wk of culture in first passage, as described previously (9). The experimental design is presented schematically in Table I; experiments are numbered for reference.

As our intent was to injure a stabilized cell layer rather than one that is rapidly growing and synthesizing elastic fibers, older cultures, usually 6 wk old, were treated with protease. As previously described, proteases were prepared, assayed, added to Dulbecco's balanced salt solution, filtered through a $0.22-\mu \mathrm{m}$ filter, reassayed, and added to cultures that had been washed with Puck's saline to remove serum (9). Incubation in the presence of protease was carried out for $45 \mathrm{~min}$ at $37^{\circ} \mathrm{C}$, after which the enzyme incubation media were removed and fresh media with serum were added. Control cultures were treated in parallel with Dulbecco's balanced salt solution. Incubation media were

1. Abbreviations used in this paper: Az, sodium azide; DES, desmosine; HNE, human neutrophil elastase; IDES, isodesmosine; PPE, porcine pancreatic elastase; PPT, porcine pancreatic trypsin. 


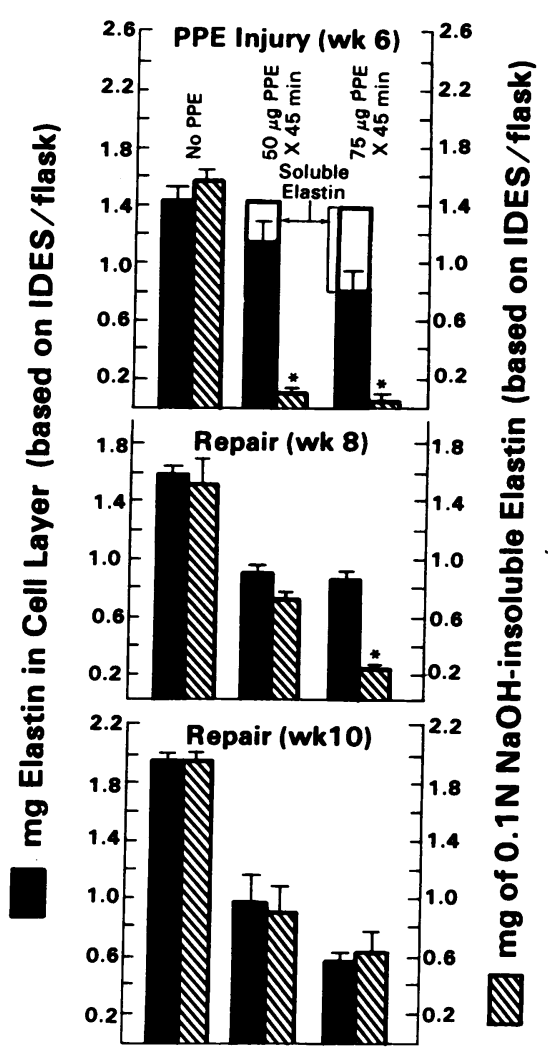

Figure 1. The effect of PPE on the elastin component of living cell layers (experiment 1 ). Note the elastin solubilized during the 45-min incubation period with PPE (calculated from the concentration of IDES + DES). More than $90 \%$ of the elastin remaining in the PPEtreated cell layer was susceptible to hot alkali treatment, in contrast to control cell layers. However, 2 wk after treatment, elastin in cell layers treated with $50 \mu \mathrm{g}$ PPE was not susceptible to hot alkali. Elastin in the cell layers treated with $75 \mu \mathrm{g}$ PPE was still significantly damaged (*) as indicated by susceptibility to hot alkali. By 4 wk after PPE treatment, elastin in both 50- and 75- $\mu$ g PPE-treated cell layers was not susceptible to hot alkali. Levels of elastin in control flasks in creased $35 \%$ during the 4-wk recovery period. The total cell layer elastin content of PPE-treated cultures was below that of the corresponding control during the recovery period. $\mathrm{m}, \mathrm{mg}$ elastin in cell layer (based on IDES/flask); 0 , $\mathrm{mg}$ of $0.1 \mathrm{~N} \mathrm{NaOH}$-insoluble elastin (based on IDES/flask).

assayed for lactate dehydrogenase (LDH) (10); another aliquot was prepared for amino acid analysis to quantify solubilized elastin and total solubilized protein. Cell layers were harvested by scraping. After homogenization, aliquots were used to measure LDH and DNA (11). Other aliquots were used for amino acid analysis and preparation of the elastin-containing residue. The residue was subjected to amino acid analysis on an amino acid analyzer (model $119 \mathrm{CL}$; Beckman Instruments, Fullerton, CA) using a program that optimized quantitation of the elastin-specific cross-link amino acids, IDES and DES, as described elsewhere (9). Selected samples were also analyzed on an amino acid analyzer (model 6300; Beckman Instruments). From the amino acid analysis, total protein present in the cell layer and collagen (from the total hydroxyproline content corrected for elastin hydroxyproline) were calculated (9). In experiment 4 , the fractions containing lysyl and IDES and DES residues were assessed for radioactivity by liquid scintillation spectrometry. Values were quench corrected and the specific radioactivity of each amino acid was calculated by dividing those values by the amount of amino acid present in the eluted material.

Quantification of elastin. Three different methods of preparing cell layer material for analysis of elastin were assessed: $(a)$ total cell layer

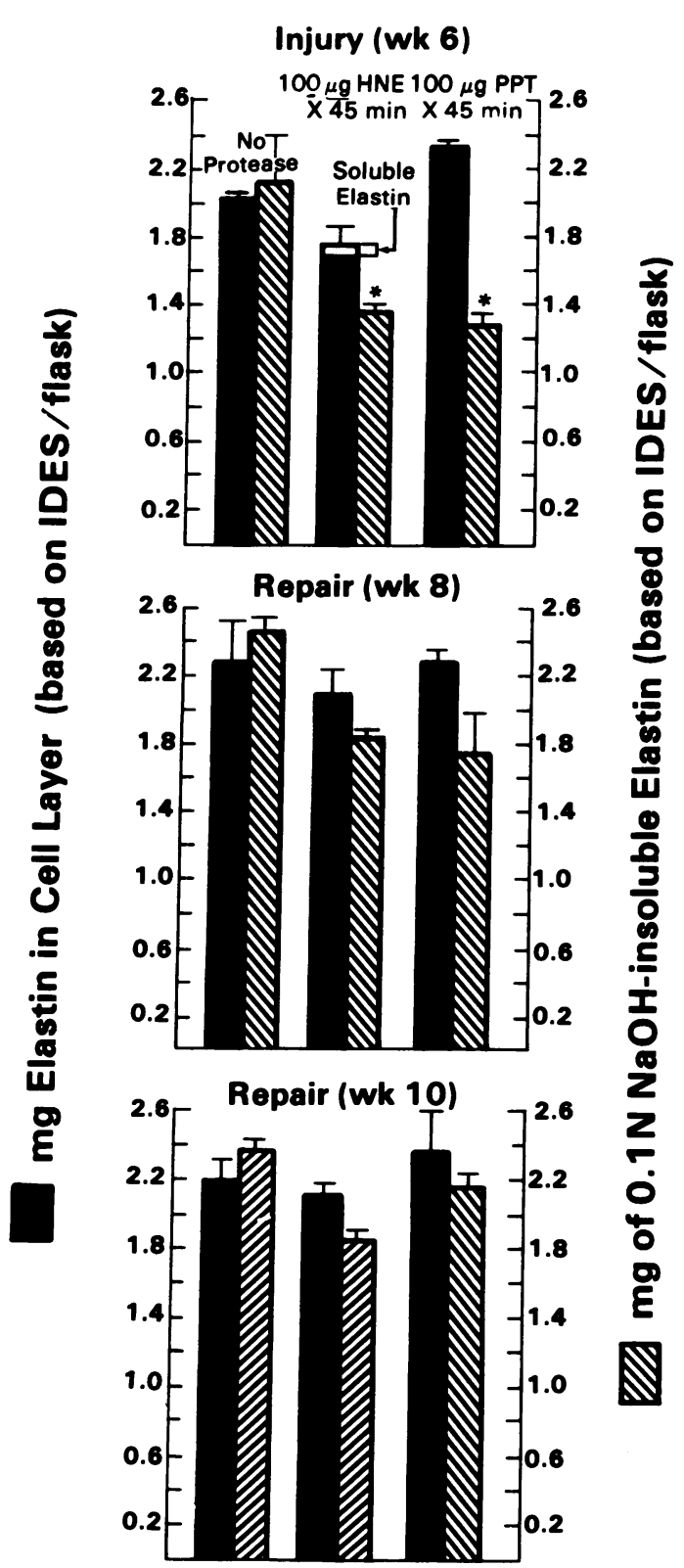

Figure 2. The effect of HNE and PPT on the elastin component of living cell layers (experiment 2). Note that little of the elastin is solubilized by HNE during the 45-min incubation period as compared with PPE, although HNE and PPE have similar elastolytic activity against elastin purified from the cell layers (9). PPT did not solubilize detectable amounts of IDES + DES. Nevertheless, the elastin of HNE and PPT treated cultures is susceptible $(*)$ to hot alkali treatment, in contrast with control cultures. By 2 wk after protease treatment, elastin in the cell layer was no longer susceptible to hot alkali extraction. $m, \mathrm{mg}$ elastin in cell layer (based on IDES/flask); $0, \mathrm{mg}$ of $0.1 \mathrm{~N} \mathrm{NaOH}$-insoluble elastin (based on IDES/flask).

elastin method. Cell layers were removed from the flasks by scraping. After homogenization, an aliquot of the suspension was lyophilized and acid hydrolyzed for amino acid analysis. Total elastin, including proteolytically degraded peptides, physically trapped in the cell layer, would be measured using this method (method 1). (b) Washed cell layer elastin method. Cell layer homogenate was prepared as above followed by centrifugation and washing of the pellet. Supernatant and pellet were hydrolyzed and analyzed as above. Trapped or loosely 


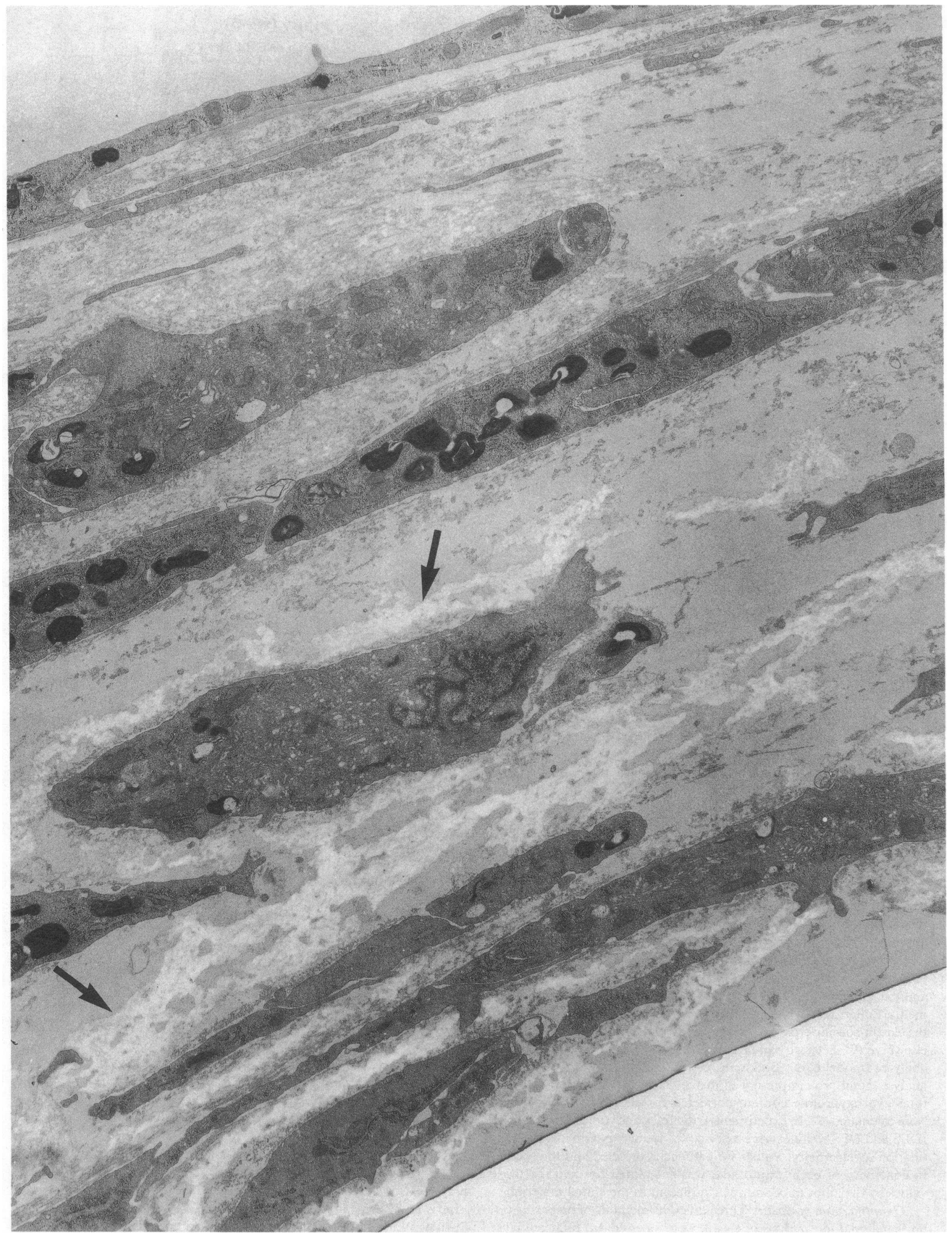


Table I. Experimental Design

\begin{tabular}{|c|c|c|c|c|c|}
\hline \multirow{3}{*}{$\begin{array}{c}\text { Exp. } \\
\text { no. }\end{array}$} & \multicolumn{3}{|c|}{ Time in first passage } & \multirow{2}{*}{\multicolumn{2}{|c|}{ Harvest }} \\
\hline & \multirow{2}{*}{$\begin{array}{l}\text { Wk 1: } \\
\text { ascorbate } \\
\text { begun* }\end{array}$} & \multirow{2}{*}{$\begin{array}{c}\text { Wk 2: } \\
\left.\text { [ }^{3} \mathrm{H}\right] \text { lysine }\end{array}$} & \multirow{2}{*}{$\begin{array}{c}\text { Wk 6: } \\
\text { protease injury }\end{array}$} & & \\
\hline & & & & D after protease & Procedure \\
\hline & & $\mu C i / f l a s k$ & & & \\
\hline 1 & + & - & $\begin{array}{c}50,75 \text {, or } 100 \\
\mu \mathrm{g} \text { PPE }\end{array}$ & 0,14 , and 28 & 1 and 3 \\
\hline 2 & + & - & $\begin{array}{c}100 \mu \mathrm{g} \mathrm{HNE} \\
\text { or PPT }\end{array}$ & 0,14 , and 28 & 1 and 3 \\
\hline \multirow[t]{2}{*}{3} & - & $10 \mu \mathrm{Ci}$ & $\begin{array}{r}50 \mu \mathrm{g} P P E \pm A z \\
-A z\end{array}$ & $\begin{array}{l}0,14, \text { and } 28 \\
0,2,7,14, \\
\text { and } 28\end{array}$ & $\begin{array}{l}1 \text { and } 3 \\
\text { Ultrastr. }\end{array}$ \\
\hline & & & $+\mathrm{Az}$ & 14 and 28 & Ultrastr. \\
\hline 4 & + & $50 \mu \mathrm{Ci}$ & $50 \mu \mathrm{g}$ PPE & $\begin{array}{l}0,14, \text { and } 28 \\
0,14 \text {, and } 28\end{array}$ & $\begin{array}{l}1 \text { and } 3 \\
\text { Ultrastr. }\end{array}$ \\
\hline 5 & + & - & $\begin{array}{c}50 \mu \mathrm{g} \text { PPE, } \\
\text { HNE, or } \\
\text { PPT, then } \\
{\left[{ }^{3} \mathrm{H}\right] \text { lysine }}\end{array}$ & 7 & 2 \\
\hline
\end{tabular}

* Cultures were grown and maintained in the presence or absence of ascorbate.

¥ Cultures were pulsed for $24 \mathrm{~h}$ on day 7 (exp. 4) or day 11 (exp. 3). 8 Cultures were washed and then incubated for $45 \mathrm{~min}$ in the presence of protease. Then the media were removed and medium with serum was added back to flasks not being harvested at that time. For exp. $3,100 \mu \mathrm{l}$ of medium containing $\mathrm{Az}$ was added $1 \mathrm{~h}$ later for a period of $24 \mathrm{~h}$. The final concentration of $\mathrm{Az}$ was $0.2 \%$. For exp. 5, treatment with protease was at wk 5; the media containing protease was removed and $50 \mu \mathrm{Ci}$ of $\left[{ }^{3} \mathrm{H}\right]$ lysine was added for $24 \mathrm{~h}$.

"Cultures were harvested at the times indicated as described in Methods and elastin was analyzed by methods 1 and 3 or by method 2. Other flasks were fixed and prepared for ultrastructure (ultrastr.). Exp., experiment.

bound elastin peptides would be found in the supernatants using this procedure (method 2). (c) Hot alkali insoluble elastin method. Homogenized cell layer was incubated in $0.1 \mathrm{~N} \mathrm{NaOH}$ at $98^{\circ} \mathrm{C}$ for $45 \mathrm{~min}$ (3), before hydrolysis and analysis (method 3 ). The insoluble residue of the hot alkali method is insoluble elastin as judged by the amino acid composition.

The quantity of elastin in the three preparations above was calculated from amino acid analysis data in two ways. The first calculation (micrograms elastin $=43 \times$ nmol of IDES + DES) was based on the mean content of DES + IDES cross-link amino acids present in the hot alkali residue of control cell layer elastin and identical to that found in rat aorta elastin (two residues per 1,000) $(9,12)$. This calculation of elastin content was suitable for use with purified elastin and cell layer preparations containing other components and was used for all three methods of cell layer processing. A second method of quantifying elastin from the total amino acid analysis could only be used with hot $\mathrm{NaOH}$-purified elastin. Elastin present (in micrograms) was calculated by multiplying the sum (in nanomoles) of all amino acid residues present by 85 (the average residue mass).
Table II. Index of Elastin Insolubility as a Measure of Repair*

\begin{tabular}{lcccc}
\hline & & \multicolumn{3}{c}{ Wk after treatment } \\
\cline { 3 - 5 } $\begin{array}{c}\text { Exp. } \\
\text { no. }\end{array}$ & $\begin{array}{c}\text { Cell layer } \\
\text { treatment }\end{array}$ & 0 & 2 & 4 \\
\hline & & \multicolumn{3}{c}{ (\% relative to control) } \\
1 & $50 \mu \mathrm{g} \mathrm{PPE}$ & $7 \pm 1(3)^{\ddagger}$ & $79 \pm 15(2)$ & $94 \pm 10(3)$ \\
& $75 \mu \mathrm{g} \mathrm{PPE}$ & $6 \pm 2(3)^{\ddagger}$ & $27 \pm 2(2)^{\ddagger}$ & $115 \pm 21(3)$ \\
2 & $100 \mu \mathrm{g} \mathrm{HNE}$ & $63 \pm 24(3)^{\ddagger}$ & $79 \pm 17(3)$ & $80 \pm 6(3)$ \\
& $100 \mu \mathrm{g} \mathrm{PPT}$ & $53 \pm 13(3)^{\ddagger}$ & $66 \pm 19(3)$ & $86 \pm 14(3)$ \\
3 & $50 \mu \mathrm{g} \mathrm{PPE}$ & $7 \pm 2(3)^{\ddagger}$ & $67 \pm 3(3)^{\ddagger}$ & $93 \pm 10(2)$ \\
4 & $50 \mu \mathrm{g} \mathrm{PPE}$ & $2 \pm 0(3)^{\ddagger}$ & - & $56 \pm 7(3)^{\ddagger}$ \\
\hline
\end{tabular}

* The susceptibility of protease-damaged elastin to hot alkali as a measure of repair. The values are expressed as the mean $\pm \mathrm{SE}$ (no. of flasks) and were calculated as described in Methods. A value of $100 \%$ would represent an index identical to that of the control flasks. In control flasks the values for the absolute amounts of hot alkali resistant elastin were compared pairwise with those for the total cell layer elastin in the same flasks; significant differences were found only at the 4-wk time point of experiment 4 (mean values of 1,143 vs. 1,799 $\mu \mathrm{g}$, respectively).

‡ Significantly different from the corresponding control cultures with respect to the proportion of total cell layer elastin that was resistant to hot alkali. After statistical comparison, ratio values were normalized as described in Methods. Exp., experiment.

Measurement of proteolytically damaged elastin and its repair. Proteolytically damaged elastin was operationally defined in two ways: as the elastin removed either during centrifugation and washing of the cell layer homogenate or by the harsher hot alkali procedure. An index of elastin insolubility as a measure of repair in each flask was calculated as $100 \times$ the micrograms of hot alkali-resistant elastin in the flask divided by the micrograms of total cell layer elastin. That ratio, representing the proportion of total cell layer elastin that was resistant to hot alkali, was then normalized by dividing by the ratio found in the control flasks (usually near unity).

Ultrastructure. Cultures were fixed in $1 \%$ glutaraldehyde buffered with $0.1 \mathrm{M}$ sodium cacodylate, rinsed in buffer, postfixed in $1 \%$ osmium tetroxide, dehydrated through a graded series of ethyl alcohols and embedded in Polybed 812 (Polysciences, Inc., Warrenton, PA) as previously described (9). Small blocks were cut from central and peripheral areas of each flask and glued to Polybed bases for sectioning. Thin sections were mounted on collodion-covered copper grids, stained with aqueous uranyl acetate and lead citrate, and then examined with a Philips 300 electron microscope.

Statistical analysis. Values given are the mean \pm SE (1 SEM). Statistical analyses involving two groups were carried out using the $t$ test for unpaired or, where noted, paired data. Comparisons involving three groups were made using analysis of variance, the Dunnett test for comparison of groups with the control group, or the Bonferroni test for comparison among all of the groups. Probability values of $P<0.05$ were considered significant.

\section{Results}

Protease-damaged elastin. Treatment of cell cultures with porcine pancreatic elastase (PPE) solubilized 10-20\% of the

Figure 3. Ultrastructure of control 6-wk-old cultures (treated with media only). The cultures studied in the experiments shown in Figs. 3-5 were grown in the absence of ascorbate. Elastic fibers (arrows) are electron lucent and are present in bands between layers of smooth muscle cells. $\times 11,200$. 


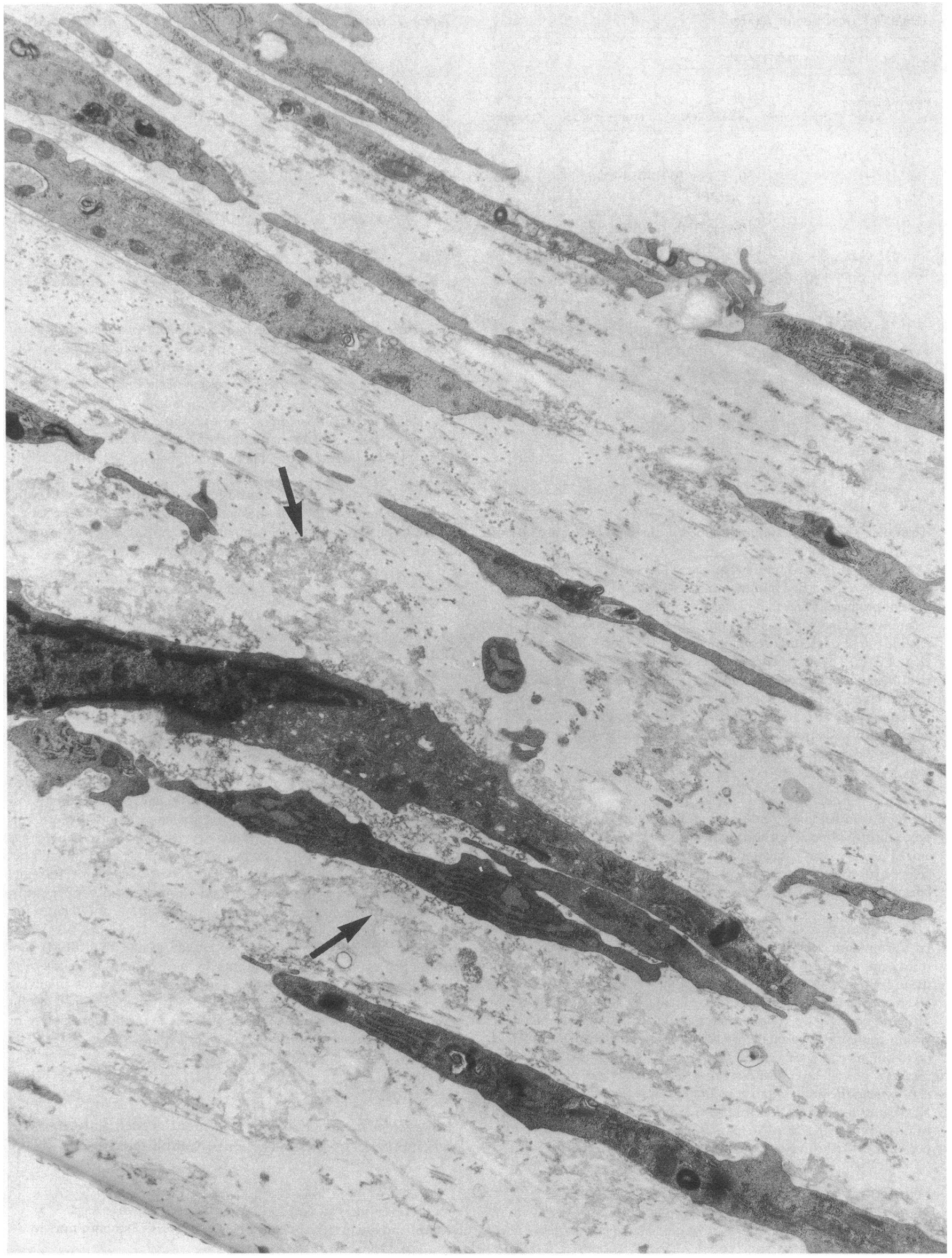


Table III. Fate of $\left[{ }^{3} \mathrm{H}\right]$ Lysine-labeled, $\mathrm{NaOH}$-resistant Elastin after PPE Treatment in Cultures Grown in the Absence of Ascorbate*

\begin{tabular}{|c|c|c|c|}
\hline \multirow[b]{2}{*}{ Elastin } & \multicolumn{3}{|c|}{ Cell layer treatment } \\
\hline & Control & $50 \mu \mathrm{g}$ PPE & $50 \mu \mathrm{g} P \mathrm{PE}+\mathrm{Az}$ \\
\hline & \multicolumn{3}{|c|}{ Immediately after treatment } \\
\hline cpm & $1,962 \pm 105(3)$ & $156 \pm 32(2)^{\ddagger}$ & - \\
\hline$\mu g$ & $1,828 \pm 222(3)$ & $98 \pm 28(3)^{\ddagger}$ & - \\
\hline \multirow[t]{2}{*}{$\mathrm{cpm} / \mu \mathrm{g}$} & $1.04 \pm 0.16$ & $1.34 \pm 0.17$ & - \\
\hline & \multicolumn{3}{|c|}{$2 \mathrm{wk}$ after treatment } \\
\hline cpm & $2,067 \pm 318(3)$ & $1,304 \pm 245(3)$ & $519 \pm 162(3)^{\ddagger}$ \\
\hline$\mu g$ & $3,706 \pm 304(3)$ & $1,950 \pm 262(3)^{\ddagger}$ & $355 \pm 117(3)^{\S}$ \\
\hline \multirow[t]{2}{*}{$\mathrm{cpm} / \mu \mathrm{g}$} & $0.54 \pm 0.05$ & $0.66 \pm 0.03$ & $1.57 \pm 0.23^{\S}$ \\
\hline & \multicolumn{3}{|c|}{$4 \mathrm{wk}$ after treatment } \\
\hline cpm & $1,816 \pm 297(3)$ & $1,635 \pm 87(3)$ & $245 \pm 55(3)^{\S}$ \\
\hline$\mu g$ & $4,753 \pm 610(3)$ & $3,506 \pm 72(2)$ & $232 \pm 21(3)^{8}$ \\
\hline $\mathrm{cpm} / \mu \mathrm{g}$ & $0.38 \pm 0.02$ & $0.47 \pm 0.03$ & $1.03 \pm 0.16^{\S}$ \\
\hline
\end{tabular}

* The fate of elastin in cultures labeled with $10 \mu \mathrm{Ci}$ of $\left[{ }^{3} \mathrm{H}\right]$ lysine on day 11 in first passage, chased, and treated with PPE on wk 6 (experiment 3). Values presented are the mean $\pm S E$ (no. of flasks).

${ }^{\ddagger}$ Significantly different with respect to the corresponding control values.

${ }^{\S}$ Significantly different with respect to the corresponding control and PPE-treated values. Values of counts per minute/microgram were calculated for each flask of a group and compared. None of the values for the $50 \mu \mathrm{g} P P E+\mathrm{Az}$ group are different from those of the group immediately after treatment with PPE.

elastin and rendered $>90 \%$ of the remaining cell layer elastin susceptible to hot alkali solubilization (Fig. 1). By contrast, elastin in control cultures was not solubilized by hot alkali treatment. 2 wk after treatment with $50 \mu \mathrm{g}$ PPE (Fig. 1), there was no hot alkali-susceptible elastin and the elastin exhibited the same amino acid composition as elastin from control cultures. Cultures treated with $75 \mu \mathrm{g}$ of PPE required 4 wk of recovery to reach this stage; with $100 \mu \mathrm{g}$ PPE, the cell layers peeled within $24 \mathrm{~h}$; therefore, this dose was not used in subsequent studies.

Cultures were also treated with $100 \mu \mathrm{g}$ of human neutrophil elastase (HNE) or porcine pancreatic trypsin (PPT) (Fig. 2). HNE solubilized only $3 \%$ of the total elastin present, whereas none was detected in the media of PPT-treated cultures. However, significant amounts of elastin in cultures treated with HNE or PPT were susceptible to hot alkali (Fig. 2). Nevertheless, the proportion of elastin that was susceptible to hot alkali was not as large as with PPE treatment (Table II). By 2 wk after treatment with HNE or PPT, the elastin present in the cell layers was resistant to hot alkali.

The increase in the proportion of hot alkali-resistant elastin with time in culture after protease treatment was quantified
Table IV. Levels of Total Cell Layer Elastin during Recovery*

\begin{tabular}{llccc}
\hline & & \multicolumn{3}{c}{ Wk after treatment } \\
\cline { 3 - 5 } $\begin{array}{c}\text { Exp. } \\
\text { no. }\end{array}$ & Treatment & 0 & 2 & 4 \\
\hline & & $\mu g$ & \multicolumn{3}{c}{$\%$ of $w k 0$} \\
1 & Control & $1,428 \pm 129(3)$ & $114 \pm 12(3)$ & $135 \pm 13(3)$ \\
& $50 \mu \mathrm{g} \mathrm{PPE}$ & $1,174 \pm 133(3)$ & $74 \pm 15(2)^{\ddagger}$ & $82 \pm 25(3)^{\ddagger}$ \\
& $75 \mu \mathrm{g}$ PPE & $817 \pm 107(3)^{\ddagger}$ & $102 \pm 17(2)^{\ddagger}$ & $66 \pm 14(3)^{\ddagger}$ \\
2 & Control & $2,030 \pm 15(2)$ & $111 \pm 12(3)$ & $108 \pm 7(3)$ \\
& $100 \mu \mathrm{g} \mathrm{HNE}$ & $1,652 \pm 98(3)^{\ddagger}$ & $124 \pm 18(3)$ & $127 \pm 11(3)$ \\
& $100 \mu \mathrm{g}$ PPT & $2,278 \pm 66(3)$ & $99 \pm 7(3)$ & $104 \pm 14(3)$ \\
3 & Control & $2,450 \pm 269(3)$ & $180 \pm 19(3)$ & $243 \pm 53(3)$ \\
& $50 \mu \mathrm{g}$ PPE & $1,705 \pm 90(3)$ & $206 \pm 19(3)$ & $265 \pm 25(3)$ \\
& $50 \mu \mathrm{g}+\mathrm{Az}$ & - & $96 \pm 21(3)^{\S}$ & $56 \pm 8(3)^{\S}$ \\
4 & Control & $860 \pm 2(3)$ & - & $209 \pm 13(3)$ \\
& $50 \mu \mathrm{g}$ PPE & $737 \pm 95(3)$ & - & $124 \pm 36(3)^{\ddagger}$
\end{tabular}

* Levels of total cell layer elastin during recovery are expressed as the mean \pm SE $\%$ of wk 0 value (no. of flasks).

‡ Significantly different with respect to the amounts of elastin present as compared with the corresponding control values.

${ }^{\S}$ Significantly different with respect to the amounts of elastin present as compared with the corresponding control and PPE-treated values. Exp., experiment.

(Table II). There was a dramatic increase in this index of elastin insolubility from a mean of only 6\%, after PPE treatment, to a mean of $90 \%, 4$ wk later. Because the initial elastin damage was not as severe in cultures treated with HNE or PPT, the recovery was not as dramatic.

Fate of protease-damaged elastin. Cell layers were labelled with $\left[{ }^{3} \mathrm{H}\right]$ lysine within the first 2 wk of culture (experiments 3 and 4). In experiment 3 , carried out in the absence of ascorbate, hot alkali-elastin-associated radioactivity in PPE-treated cultures recovered to within $93 \%$ of control values during the 4-wk period after treatment (Table III). Although the initial amount of cell layer elastin and the associated radioactivity were reduced by PPE solubilization, this data indicated reincorporation of proteolytically damaged elastin into hot alkaliresistant material. Hot alkali-resistant elastin and total cell layer elastin were 74 and $76 \%$ of control values, respectively (Tables III and IV). As expected, the level of radioactivity in the hot alkali-resistant elastin of control cultures was the same at all time points.

The specific radioactivity values of the elastin in the PPEtreated cultures after 4 wk of recovery was not significantly lower than that of the corresponding controls. This would not be the case if PPE-damaged elastin had been debrided and replaced by new elastin. With both control and PPE-treated cultures, the decrease in the specific radioactivity of elastin with time reflected a proportional increase in the amount of hot alkali resistant elastin due to biosynthesis.

In the second experiment with $\left[{ }^{3} \mathrm{H}\right]$ lysine-labeled cultures (no. 4), IDES and DES residues exhibited similar levels of

Figure 4. Ultrastructure of severely damaged area of a PPE-treated culture immediately after exposure to PPE (50 $\mu \mathrm{g} \times 45 \mathrm{~min})$. Elastic fibers (arrows) are electron dense and appear frayed. $\times 12,900$. 


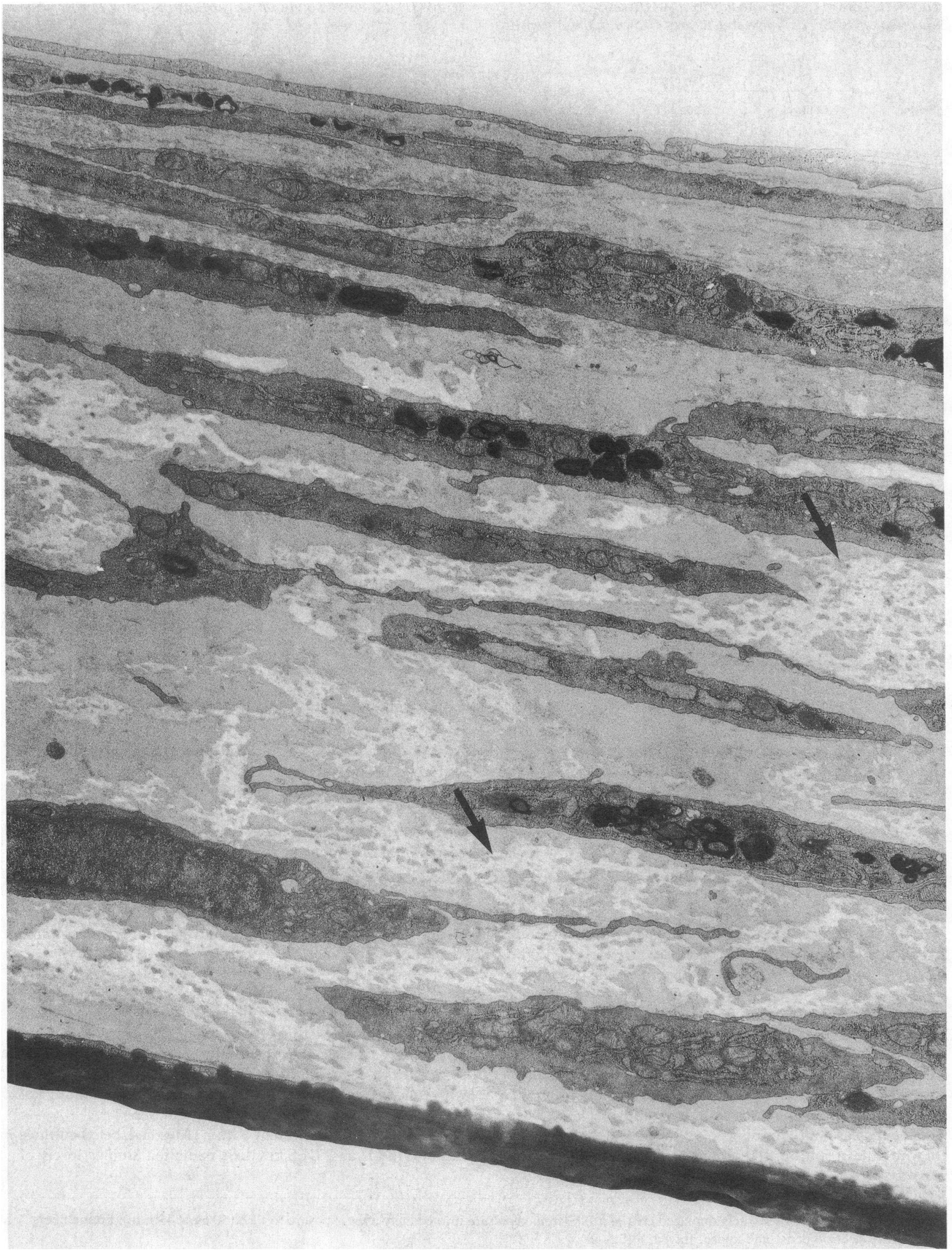


Table V. Production and Accumulation of Elastin during the First Week after Protease Treatment*

\begin{tabular}{lccc}
\hline & & \multicolumn{2}{c}{1 wk later } \\
\cline { 3 - 4 } Treatment & $\begin{array}{c}\text { Insoluble elastin } \\
\text { after treatment }\end{array}$ & Elastin & IDES \pm DES \\
\hline & $\mu g$ & \% of $w k 0$ & $c p m$ \\
Control & $1,919 \pm 91(3)$ & $157 \pm 12(3)$ & $91,012 \pm 5,667(3)$ \\
$50 \mu \mathrm{g} \mathrm{PPE}$ & $1,705 \pm 500(2)$ & $135 \pm 10(3)$ & $73,029 \pm 6,749(3)$ \\
$50 \mu \mathrm{g} \mathrm{HNE}$ & $2,086 \pm 230(2)$ & $125 \pm 18(3)$ & $87,504 \pm 12,328(3)$ \\
$50 \mu \mathrm{g}$ PPT & $2,151 \pm 157(2)$ & $154 \pm 54(3)$ & $73,689 \pm 9,644(3)$
\end{tabular}

* Mean \pm SE (no. of flasks) values for washed cell layer elastin in 6-wk-old cultures after protease treatment. The elastin values after 1 wk of recovery are expressed as a percent of the latter values. PPE treatment solubilized $176 \pm 16 \mu \mathrm{g}(n=7)$ of elastin and an additional 35-55 $\mu \mathrm{g}$ could be removed by homogenizing and washing the cell layer. HNE solubilized only $14 \pm 4 \mu \mathrm{g}(n=7)$ of elastin. After treatment, some flasks were harvested and others pulsed with $50 \mu \mathrm{Ci}$ of $\left[{ }^{3} \mathrm{H}\right]$ lysine for $1 \mathrm{~d}$ and chased for another $6 \mathrm{~d}$ (experiment 5 ). There are no significant differences in this Table.

specific radioactivity. There were no differences between the specific radioactivity of IDES + DES residues from cultures that had been treated with PPE 4 wk earlier and their controls (data not shown). However, incomplete repair was observed in this experiment 4 wk after injury (Table II).

To study hot alkali-susceptible elastin, we carried out amino acid analysis on the hot alkali supernatant material from one flask after PPE treatment. The expected amounts of IDES + DES were found and their specific radioactivities were comparable to IDES + DES from the control cell layers.

Effect of azide on repair. Killing of the cell layer $1 \mathrm{~h}$ after PPE treatment was carried out to examine the possibility that repair might occur in the extracellular matrix without the contribution of intact cells or their synthesized products. As little as a 1-h recovery period in medium containing serum allowed the somewhat rounded PPE-treated cells to return to their flattened conformation before the addition of sodium azide (Az) (9). In an initial experiment to study the effects of $\mathrm{Az}$, cultures were treated for $1 \mathrm{~d}$ with medium containing concentrations of $\mathrm{Az}$ up to $0.4 \%$ followed by another $4 \mathrm{~d}$ in Az-free medium (not shown). Proteases were not used. The effect was a $95 \%$ loss of LDH from the cell layer during that time and a $35 \%$ decrease in DNA content. At the same time we found no loss of elastin.

After PPE treatment, there was no repair in the Az-treated cultures; there was no increase in hot alkali-resistant elastin during the subsequent 4-wk period (Table III). The amount of total cell layer elastin decreased by $44 \%$ and may have represented preferential loss into the media of the PPE-damaged portions of elastin in the absence of repair (Table IV). Meanwhile, Az-treated cultures exhibited a 59\% decrease in total protein from the $6,859 \mu \mathrm{g}$ present immediately after PPEtreatment (not shown). The specific radioactivity of the elastin in the Az-treated cultures at 2 and 4 wk was not different from the levels found at the time of injury. This suggested that no new insoluble elastin was accumulating in the cultures after treatment with Az. By comparison cultures treated with PPE, but not Az, exhibited a 2.65-fold increase in total cell layer elastin and a 2.65-fold increase in hot alkali-insoluble elastin with a 2.85 -fold decrease in elastin specific radioactivity (Tables III and IV).

Levels of elastin and collagen during the recovery phase. At no time during the 4-wk recovery period after protease treatment did we find elevated levels of either total cell layer elastin or collagen as compared with control cell layers. This observation was made whether cell layers were isolated by homogenization followed by centrifugation and washing or by homogenization only. Nor was the collagen content different among the groups immediately after treatment (not shown).

In those experiments where the cell cultures were supplemented with ascorbate, the amount of total cell layer elastin was below that of the corresponding controls 4 wk after PPE treatment (experiments 1 and 4, Table IV). 4 wk after treatment with $75 \mu \mathrm{g}$ of PPE, a significant depression of insoluble collagen as compared with the control was also found (PPE treated $=1,120 \pm 68 \mu \mathrm{g}, \mathrm{n}=3$, and control $=1,714 \pm 57 \mu \mathrm{g}$ per flask, $n=3$ ). Nevertheless, DNA and LDH values, indicators of cell number and cell viability, were not lower for flasks treated with $75 \mu \mathrm{g}$ of PPE as compared with control flasks at any of the study times (not shown). In this experiment, the injury to the extracellular matrix might have been so severe as to destroy the scaffolding for new elastin or collagen incorporation.

A more sensitive method of measuring the effect of protease treatment on the incorporation of new elastin and collagen, used cultures that were pulsed with $\left[{ }^{3} \mathrm{H}\right]$ lysine immediately after protease treatment (Table V). Protease-treated cultures as compared with control cultures exhibited similar incorporation of radioactive lysine into IDES/DES. As ultrastructural repair is only evident near the top of the culture at 2 $\mathrm{d}$, it is possible that the pulse period during the first $24 \mathrm{~h}$ after PPE injury is too early to detect an increase in $\left[{ }^{3} \mathrm{H}\right]$ lysine incorporation into elastin (Table V). Similarly, there was no increase in collagen incorporation, based upon pulse-chase into $\left[{ }^{3} \mathrm{H}\right.$ ]hydroxylysine, after protease treatment (data not shown).

Repair at the ultrastructural level. Repair at the ultrastructural level was also observed. At the time of injury, the continuous bands of amorphous elastin found in the bottom half of control cultures (Fig. 3) were frayed, fragmented, and electron dense in many areas of the PPE-treated cultures as previously described (Fig. 4) (8, 9). The small clumps of amorphous elastin that remained in these areas were surrounded by frayed elastin and appeared to be in central regions of the elastic fiber that the enzyme had not penetrated. $2 \mathrm{~d}$ after PPE treatment, extensive fragmentation was still apparent (not shown). By $7 \mathrm{~d}$, frayed elastic fibers were no longer evident and electron lucent bands were again visible (Fig. 5). However, these bands often lacked the thickness and uniformity of elastin bands in control cultures. By 2 wk after PPE treatment, the cultures could not be distinguished from controls (Fig. 6). By contrast, 2 wk after

Figure 5. Ultrastructure of cultures $7 \mathrm{~d}$ after PPE treatment. At this time severely damaged areas can no longer be found and elastic fibers (arrows) are again electron lucent and organized in bands, although lacking the thickness and uniformity of elastin bands in control cultures. $\times 15,000$. 


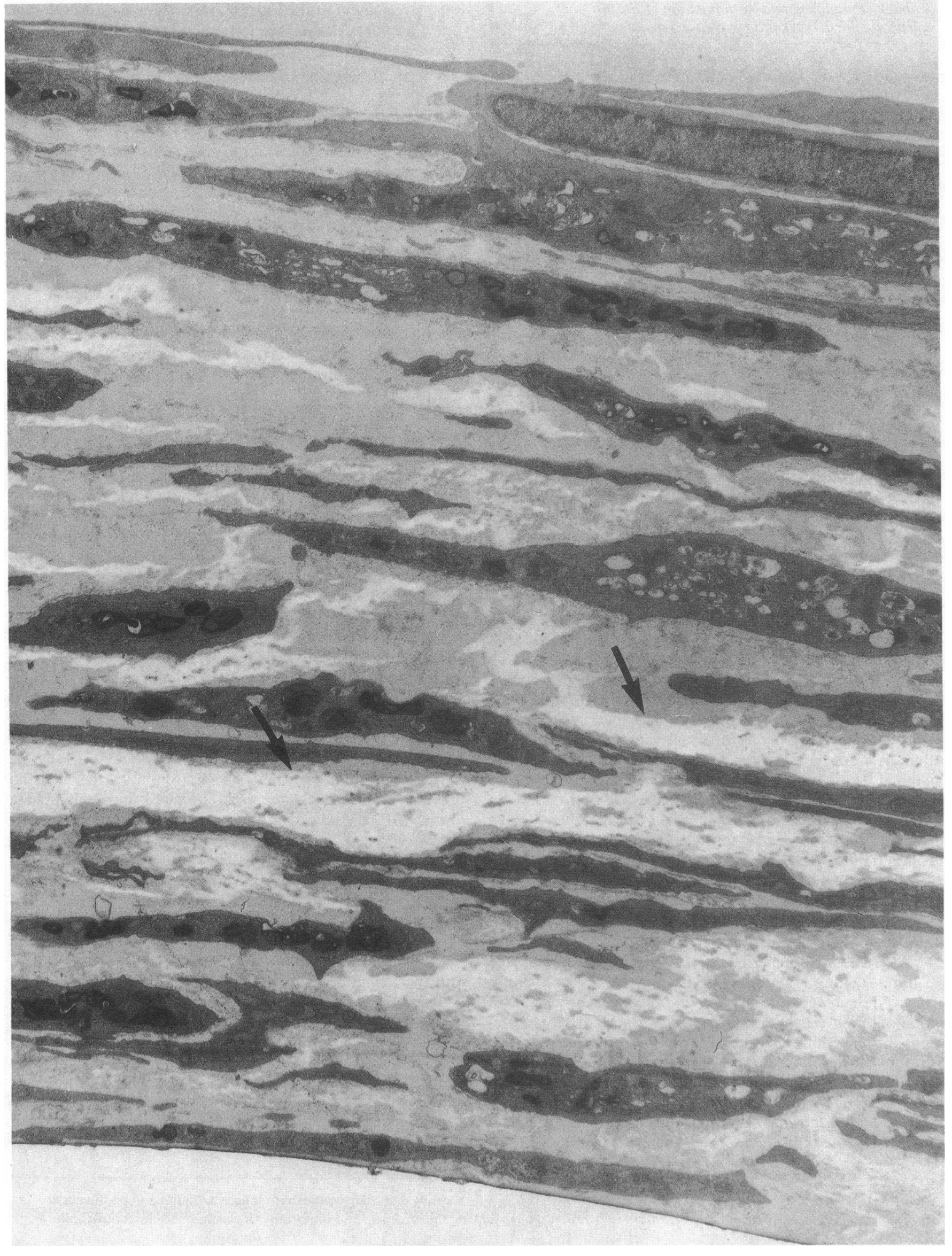


treatment with PPE followed by azide, there was little amorphous elastin seen (not shown) and significant amounts of fragmented elastin were still present.

\section{Discussion}

In our smooth muscle cell cultures, we have consistently observed a combination of two levels of proteolytic injury to the elastin, one being frank solubilization and, the other, presumed peptide bond hydrolysis without concomitant solubilization of elastin. Frank solubilization was observed to a large degree with PPE, whereas HNE injury resulted in much less solubilization and is presumed to be dominated by peptide bond hydrolysis. The latter injury could be assessed by probing the cell layer with hot $\mathrm{NaOH}$. Within $4 \mathrm{wk}$, a salvage repair process converted most of the hot alkali-susceptible, proteasedamaged elastin to hot alkali-resistant elastin. The most dramatic repair was observed after PPE treatment, where damaged but insoluble elastin was almost entirely susceptible to subsequent solubilization with hot alkali treatment, but $>90 \%$ resistant 4 wk later. Such results correlated well with ultrastructural analyses that showed extensive amounts of fragmented elastin after PPE injury followed by the reappearance of bands of electron-lucent elastin after 2 wk of repair.

Additional data suggested that the hot alkali-susceptible elastin present immediately after injury was reintegrated with time into a hot alkali-resistant form. Debridement as a significant mechanism of repair in the cell culture system thus was excluded. As we have not added inflammatory cells to the injured cell layers, these results do not exclude debridement of elastin in vivo.

Although newly synthesized tropoelastin molecules may play a role in the restoration of hot alkali resistance, proteasetreated cultures did not exhibit increased levels of total cell layer elastin, as compared with the controls, during the 4-wk recovery period. Nor was there greater incorporation of newly synthesized tropoelastin within $1 \mathrm{~d}$ after injury as compared with the controls. Indeed, in two experiments, nos. 1 and 4, those amounts were below the corresponding 4-wk controls. Furthermore, those amounts had not increased from the levels found immediately after treatment, suggesting that little new tropoelastin incorporation was required for repair of this type of injury. However, repair did not occur if the cells were killed. In a separate study, a two-to-threefold increase in $\left[{ }^{3} \mathrm{H}\right]$ valine incorporation into nondialyzable radioactivity was observed 1 d after PPE treatment (8). Combined with our present findings, this suggests that a PPE-treated cell layer may provide a less efficient matrix for the incorporation of new tropoelastin molecules.

Injury of elastin with either $100 \mu \mathrm{g}$ of PPT or HNE resulted in less injury than with $50 \mu \mathrm{g}$ of PPE, as measured by hot alkali susceptibility and repair was complete within $2 \mathrm{wk}$. There was a dose-response effect for repair of PPE injury. Injury by $75 \mu \mathrm{g}$ PPE required $4 \mathrm{wk}$ for restoration of hot alkali resistance to the elastin as compared with 2 wk for cultures treated with $50 \mu \mathrm{g}$ of PPE in the same experiment.
A number of in vivo studies involving proteolysis of elastin contain observations that are consistent with this novel repair mechanism (13-15). There is chemical evidence that damage to the elastin in the human aorta accumulates with age (16). A recent report by Halme and co-workers (17) demonstrated a new cyclic amino acid in the alkali hydrolysate of aortic elastin from older humans. In discussing the origin of this crosslink, they hypothesized that "during aging, nonspecific proteinases might cleave the elastin peptides outside the crosslinked stable network."

It is possible to derive insights into the properties of native or proteolytically damaged elastic fibers by considering their susceptibility to hot $\mathrm{NaOH}$. It is also instructive to consider the resistance of elastin even to hot $1.0 \mathrm{~N} \mathrm{NaOH}$ as compared with its susceptibility to solubilization by alcoholic $1.0 \mathrm{~N} \mathrm{KOH}$ at room temperature $(18,19)$. The extreme hydrophobicity of elastin is well known, as is the stabilization of hydrophobic forces by elevated temperatures $(20,21)$. Hot alkali treatment of elastin increases the number of $\mathrm{NH}_{2}$-terminal amino acids per 1,000 residues by only two to three $(22,23)$. These new $\mathrm{NH}_{2}$-terminal amino acids are probably concentrated on the surface of the elastic fiber. Robert and Poullain (19) have shown that the addition of $80 \%$ ethanol to the alkali results in the solubilization of elastin even at room temperature. This addition of alcohol to the solvent decreases the intraelastin hydrophobic forces, facilitating penetration of the alkali into the elastic fiber $(19,21)$. Salvage repair of elastin may consist of restoring the hydrophobicity and, concomitantly, the resistance to hot alkali. At the ultrastructural level, this restoration may be associated with the renewed ability to exclude the aqueous electron-dense stain.

There is as yet little information available on possible repair mechanisms. However, from observations made on the in vitro and in vivo models and consideration of the normal elastin maturation process, it is intriguing to hypothesize the following mechanism. The first step in the re-zippering of an enzymatically hydrolyzed peptide bond in elastin may involve formation of a Schiff base linkage between the new $\mathrm{NH}_{2}$-terminal alpha-amino group and a peptidyl aldehyde group derived from a lysyl residue, leading to formation of a unique crosslink amino acid. Schiff base formation is also a key step in the cross-linking of tropoelastin monomers, through lysyl-derived residues, into mature, insoluble elastin (24). The origins of the lysyl residue could include the peptide backbone of existing elastin or, even, newly synthesized tropoelastin. In either case, the requirement for oxidation of the side chain of that lysyl residue implies that lysyl oxidase may play an important role not only in the early development of elastin, but also in its repair.

An interesting feature of this proposed mechanism is that repair is unlikely to restore the original peptide bonds. Therefore, the primary structure and the elastic properties of the repaired elastin, are likely to be altered and possibly weakened as compared with the original native elastin. Under mechanical stress, tearing might occur; however, the elastic properties of the repaired elastin would clearly be strengthened as compared with the proteolytically damaged elastin. The carboxyl

Figure 6. Ultrastructure of cultures 2 wk after PPE treatment. Elastic fibers (arrows) are electron lucent, organized in bands, and difficult to distinguish from controls. $\times 11,200$. 
group that resulted from the proteolytic hydrolysis of the peptide bond might remain after the repair process is complete. This new carboxyl group would modify the extreme hydrophobicity of the elastin in that microenvironment and could serve as a potential calcification site. At the level of the electron microscope, calcium crystals are found among elastic fibers in atherosclerotic lesions (25).

Proteolysis of elastin may hydrolyze many peptide bonds; nevertheless, much of the proteolytically damaged elastin may remain insoluble or trapped within the extracellular matrix and repaired as described above. Interference with this mechanism, rather than frank solubilization of elastin, may be an important factor in pathologies involving elastin proteolysis. Because elastin is a highly cross-linked biopolymer, it may be one of the few proteins that does not appear to turnover significantly during the lifetime of the animal, except under pathologic conditions (26). Data derived from an earlier study of this in vitro model suggested partial protection of the elastic fibers against accidental proteolysis by HNE (9). However, as a result of small repetitive insults to the fiber, repair cross-links might accumulate over time. This process could lead to progressive changes in the tensile properties of elastin. Such alterations might be associated with the impairment of elastic recoil and loss of function.

\section{Acknowledgments}

This work was supported by National Heart, Lung, and Blood Institute grants HL-19717 and HL-33522.

\section{References}

1. Davidson, J. M., and M. G. Giro. 1986. Control of elastin synthesis: molecular and cellular aspects. In Regulation of Matrix Accumulation. R. P. Mecham, editor. Academic Press, Inc., New York. 177-216.

2. Bieth, J. G. 1986. Elastases: catalytic and biological properties. In Regulation of Matrix Accumulation. R. P. Mecham, editor. Academic Press, Inc., New York. 217-320.

3. Lansing, A. I., T. B. Rosenthal, M. Alex, and E. W. Dempsey. 1952. The structure and characterization of elastic fibers as revealed by elastase and by electron microscopy. Anat. Rec. 114:555-570.

4. Senior, R. M., G. L. Griffin, and R. P. Mecham. 1980. Chemotactic activity of elastin-derived peptides. J. Clin. Invest. 66:859-862.

5. Senior, R. M., G. L. Griffin, R. P. Mecham, D. S. Wrenn, K. U. Prasad, and D. W. Urry. 1984. Val-Gly-Val-Ala-Pro-Gly', a repeating peptide in elastin, is chemotactic for fibroblasts and monocytes. J. Cell Biol. 99:870-875.

6. Fulop, T., Jr., M. P. Jacob, Z. Varga, G. Foris, A. Leovey, and L. Robert. 1986. Effect of elastin peptides on human monocytes: $\mathrm{Ca}^{2+}$ mobilization, stimulation of respiratory burst and enzyme secretion. Biochem. Biophys. Res. Commun. 141:92-98.

7. Jacob, M. P., T. Fulop, Jr., G. Foris, and L. Robert. 1987. Effect of elastin peptides on ion fluxes in mononuclear cells, fibroblasts, and smooth muscle cells. Proc. Natl. Acad. Sci. USA. 84:995-999.

8. Faris, B., P. Toselli, J. Kispert, B. L. Wolfe, C. A. Pratt, P. J. Mogayzel, Jr., and C. Franzblau. 1986. Elastase effect on the extracellular matrix of rat aortic smooth muscle cells in culture. Exp. Mol. Pathol. 45:105-117.

9. Stone, P. J., M. P. McMahon, S. M. Morris, J. D. Calore, and C. Franzblau. 1987. Elastin in a neonatal rat smooth muscle cell culture has greatly decreased susceptibility to proteolysis by human neutrophil elastase. An in vitro model of elastolytic injury. In Vitro (Rockville). 23:663-676.

10. Worthington Enzymes. 1978. Worthington Biochemicals Inc., Freehold, NJ. 111-112.

11. Burton, K. 1956. A study of the conditions and mechanism of the diphenylamine reaction for the colorimetric estimation of deoxyribonucleic acid. Biochem. J. 62:315-323.

12. Starcher, B. C., and M. J. Galione. 1976. Purification and comparison of elastins from different animal species. Anal. Biochem. 74:441-447.

13. Kuhn, C. III, S. Y. Yu, M. Chraplyvy, H. E. Linder, and R. M. Senior. 1976. The induction of emphysema with elastase. II. Changes in connective tissue. Lab. Invest. 34:372-380.

14. Lefevre, M., and R. B. Rucker. 1980. Aorta elastin turnover in normal and hypercholesterolemic Japanese quail. Biochim. Biophys. Acta. 630:519-529.

15. Lefevre, M., and R. B. Rucker. 1983. Effects of age and diet on changes in the $\mathrm{N}$-terminal amino acid content of aorta elastin. Biochim. Biophys. Acta. 743:338-342.

16. Robert, L. 1977. Turnover and elastolysis in elastic tissue. $A d v$. Exp. Med. Biol. 79:139-143.

17. Halme, T., M. Jutila, T. Vihersaari, P. Oksman, N. D. Light, and R. Penttinen. 1985. The borohydride-reducible compounds of human aortic elastin. Biochem. J. 232:169-175.

18. Partridge, S. M. 1962. Elastin. Adv. Protein Chem. 17:227-302.

19. Robert, L., and N. Poullain. 1963. Studies on the structure of elastin and the mode of action of elastase. I. A new method of preparing a soluble derivative of elastin. Bull. Soc. Chim. Biol. 45:1317-1326.

20. Van Holde, K. E. 1971. Physical Biochemistry. Prentice-Hall, Inc., Englewood Cliffs, NJ. 22.

21. Gosline, J. M. 1976. The physical properties of elastic tissue. Int. Rev. Connect. Tissue Res. 7:211-249.

22. Rasmussen, B. L., E. Bruenger, and L. B. Sandberg. 1975. A new method for purification of mature elastin. Anal. Biochem. 64:255-259.

23. Soskel, N. T., and L. B. Sandberg. 1983. A comparison of six methods of extracting elastin residue from hamster lungs. Exp. Lung Res. 4:109-119.

24. Kagan, H. M., and K. A. Sullivan. 1982. Lysyl oxidase: preparation and role in elastin biosynthesis. Methods Enzymol. 82A:637650.

25. Yu, S. Y., and H. T. Blumenthal. 1967. The calcification of elastic tissue. In The Connective Tissue. B. M. Wagner and D. E. Smith, editors. Williams and Wilkins, Baltimore, MD. 17-49.

26. Rucker, R. B., and M. A. Dubick. 1984. Elastin metabolism and chemistry: potential roles in lung development and structure. $E n$ viron. Health Perspect. 55:179-184. 